\title{
Reduction of Empathy for Pain by Placebo Analgesia Suggests Functional Equivalence of Empathy and First-Hand Emotion Experience
}

\author{
Markus Rütgen, ${ }^{1}$ Eva-Maria Seidel, ${ }^{1}$ Igor Riečanský, ${ }^{1,2}$ and ${ }^{\circledR C}$ Claus Lamm ${ }^{1}$ \\ ${ }^{1}$ Social, Cognitive and Affective Neuroscience Unit, Department of Basic Psychological Research and Research Methods, Faculty of Psychology, University \\ of Vienna, 1010 Vienna, Austria, and ${ }^{2}$ Laboratory of Cognitive Neuroscience, Institute of Normal and Pathological Physiology, Slovak Academy of Sciences, \\ 81371 Bratislava, Slovakia
}

Previous research in social neuroscience has consistently shown that empathy for pain recruits brain areas that are also activated during the first-hand experience of pain. This has been interpreted as evidence that empathy relies upon neural processes similar to those underpinning the first-hand experience of emotions. However, whether such overlapping neural activations imply that equivalent neural functions are engaged by empathy and direct emotion experiences remains to be demonstrated. We induced placebo analgesia, a phenomenon specifically modulating the first-hand experience of pain, to test whether this also reduces empathy for pain. Subjective and neural measures of pain and empathy for pain were collected using self-report and event-related potentials (ERPs) while participants underwent painful electrical stimulation or witnessed that another person was undergoing such stimulation. Self-report showed decreased empathy during placebo analgesia, and this was mirrored by reduced amplitudes of the pain-related P2, an ERP component indexing neural computations related to the affective-motivational component of pain. Moreover, these effects were specific for pain, as self-report and ERP measures of control conditions unrelated to pain were not affected by placebo analgesia. Together, the present results suggest that empathy seems to rely on neural processes that are (partially) functionally equivalent to those engaged by first-hand emotion experiences. Moreover, they imply that analgesics may have the unwanted side effect of reducing empathic resonance and concern for others.

Key words: empathy; ERP; P2; pain; placebo analgesia

\section{Introduction}

Empathy plays a key role in human social interaction. It is an important motivator of prosocial behavior, and it allows us to share and to understand the emotions of others. Recent social neuroscience models suggest that empathy relies upon simulating other's emotions grounded in neural and bodily functions that are engaged during first-hand emotion experiences (Bastiaansen et al., 2009; Singer and Lamm, 2009; Decety, 2010). For instance, fMRI studies have consistently shown that empathy for pain activates brain areas overlapping with those that are activated during the first-hand experience of pain (Lamm et al., 2011, for meta-analysis), and this finding also extends to affective ex-

Received Sept. 23, 2014; revised April 17, 2015; accepted April 20, 2015.

Author contributions: M.R., E.-M.S., I.R., and C.L. designed research; M.R. and E.-M.S. performed research; M.R., E.-M.S., and I.R. analyzed data; M.R., E.-M.S., I.R., and C.L. wrote the paper.

This work was supported by the Vienna Science and Technology Fund (WWTF; Project CS11-016). We thank Alexander Kudrna for assistance with EEG measurements; Franziska Pisch for serving as the confederate of this study; Christoph Eisenegger and Giorgia Silani for critical feedback on an earlier version of this paper; and the two anonymous reviewers for helpful comments to improve the manuscript.

The authors declare no competing financial interests.

Correspondence should be addressed to Dr. Claus Lamm, Social, Cognitive and Affective Neuroscience Unit, Department of Basic Psychological Research and Research Methods, Faculty of Psychology, University of Vienna, Liebiggasse 5, 1010 Vienna, Austria. E-mail: claus.lamm@univie.ac.at.

DOI:10.1523/JNEUROSCI.3936-14.2015

Copyright $\odot 2015$ the authors $\quad 0270-6474 / 15 / 358938-10 \$ 15.00 / 0$ periences other than pain (Fan et al., 2011, for meta-analysis; see also Lamm et al., 2015).

However, simulation models of empathy suffer from a central explanatory gap, which is that an overlap of neural activations does not necessarily imply that the same neural mechanisms are engaged. Indeed, it is well known in fMRI research that one and the same brain structure can be activated by a variety of tasks and functions (e.g., Grill-Spector and Malach, 2001; Poldrack, 2006). Hence, shared activations and neural correlate measures of empathy alone cannot explain that empathy indeed relies on the same neural mechanisms as the corresponding first-hand emotion experience. What is needed is a more causal demonstration, such as that the experimental modulation of the first-hand emotion experience in an equivalent fashion also modulates empathy for that emotion experience. Only then would the overlapping neural circuitry speak for a representation of the other's emotion that is specifically grounded in those neural mechanisms that are also subserving the corresponding first-hand emotion experience, as opposed to unspecific or domain-general neural processes associated with emotion experiences (for in-depth discussion, see also Eisenberger, 2015; Lamm and Majdandžić, 2015).

In the present work, we therefore used a placebo analgesia induction procedure known to reduce the first-hand experience of pain, and tested whether this also modulates empathy for pain. 
Placebo analgesia denotes pain reduction after administration of an inactive compound promoted as a potent painkiller (Benedetti et al., 2005; Hoffman et al., 2005). Its effects have, among others, been related to modulation of activity in a subdivision of mid-cingulate cortex (MCC) (Scott et al., 2008) related to the affective dimension of pain (Shackman et al., 2011). Current consensus explains placebo analgesia as an expectation and learning phenomenon by which the placebo treatment becomes associated with pain reduction, and in which pain reduction can be generated very specifically without unspecific affective or pharmacological side effects (for review, see Colloca et al., 2013).

Compared with hemodynamic measurements, electroencephalographic event-related potentials (ERPs) have the advantage of being more direct measures of neural activity and providing temporally precise information on the dynamics of neural processing. Painful stimulation has been shown to generate a late ERP component, the so-called P2 (Becker et al., 1993; Garcia-Larrea et al., 2003; Dowman, 2004). This component is likely related to activity in MCC, although other areas might contribute to P2 as well (see Perchet et al., 2008). Crucially, placebo analgesia results in substantially reduced P2 amplitudes during pain (Wager et al., 2006; Watson et al., 2007). In addition to self-report measures of empathy, we therefore investigated experimental modulation of the P2 ERP component to test whether the predicted "placebo empathy analgesia" is mediated by the same neural processes as placebo analgesia itself. This was based on the rationale that $\mathrm{P} 2$ reflects neural computations specifically related to the first-hand experience of pain. If these computations were modulated by placebo analgesia not only when experiencing pain oneself, but also when witnessing someone else's pain, this would suggest that similar neural processes are engaged in both conditions.

\section{Materials and Methods}

\section{Participants}

Forty-five healthy right-handed volunteers (Vienna university students) were randomly assigned to a control $(n=20 ; 13$ females) or a placebo group ( $n=25,10$ females). The higher number of participants in the placebo group was chosen to account for the exclusion of possible nonresponders. Seven participants in total had to be excluded from the analysis: two control group participants because of partial malfunctioning of the pain stimulation device; five participants of the placebo group because they did not respond to the placebo induction (for detailed exclusion procedure, see Procedures). All analyses reported in the paper were performed for the remaining 38 participants (control group: $n=18,13$ females, 5 males, mean age \pm SEM $=26.72 \pm 1.23$ years; placebo group: $n=20$, 9 females, 11 males, mean age \pm SEM $=25.80 \pm 1.29$ years). Because exploratory analyses did not yield gender-related effects (all $p$ values $>0.207$ ), all analyses were performed without gender as a factor.

The study was approved by the Ethics Committee of the Medical University of Vienna and performed in line with the Declaration of Helsinki (1964). Participants signed written informed consent and received a reimbursement of $€ 40$ for their participation.

\section{Experimental task and trial structure}

We used a well-established empathy for pain paradigm (Singer et al., 2004) in which participants were either exposed to short-lasting (duration $=500 \mathrm{~ms}$ ) and individually calibrated painful or nonpainful electrical stimulation themselves, or indirectly witnessed delivery of such stimulation to another person (which in reality was a confederate of the experimenter). The inclusion of nonpainful stimuli in our design was an important asset for testing the specificity of the expected effects, as placebo analgesia should only affect the processing of painful stimuli. Electrical stimulation was delivered using a Digitimer DS5 Isolated Bipolar Constant Current Stimulator (Digitimer Clinical and Biomedical Research Instruments) via a concentric surface electrode with $7 \mathrm{~mm}$ diam- eter and a platinum pin (WASP electrode, Specialty Developments) attached to the back of the right hand. The type and the duration of stimulation were motivated by previous empathy studies, which had successfully instigated reliable empathic responses and their neural concomitants using an identical setup (e.g., Singer et al., 2004, 2006, 2008; Hein et al., 2011). Although conventional cutaneous bipolar electrodes recruited large-diameter sensory fibers, the concentric electrodes we used are very reliable in producing pain-evoked potentials resulting from superficial skin layer (i.e., A $\delta$ fiber stimulation) (Katsarava et al., 2006; Lefaucheur et al., 2012). Perchet et al. (2012) further showed similar P2 amplitudes using concentric electrodes and laser stimulation in the same subjects. Moreover, electrical pain has the practical advantage of a faster onset and offset time compared with thermal pain.

The trial structure and timing were as follows (Fig. 1). First, the target of the upcoming electrical stimulation (i.e., either participant or other person) was indicated on the computer screen by an arrow pointing either to the participant or to the other person (duration $=2000 \mathrm{~ms}$ ), followed by a visual cue (duration $=500 \mathrm{~ms}$ ) indicating the intensity of the upcoming stimulus (henceforth referred to as "anticipation cue"; orange $=$ painful; blue $=$ nonpainful). After a blank screen (duration $=$ $3500 \mathrm{~ms}$ ), the electrical stimulus (duration $=500 \mathrm{~ms}$ ) was delivered while another visual cue indicating stimulus intensity was simultaneously shown on the screen (henceforth referred to as "delivery cue"; red $=$ painful; green $=$ nonpainful, duration $=1000 \mathrm{~ms}$ ). Importantly, this setup enabled participants to know how and when the other person was stimulated in the absence of direct observation of her actual reactions. Hence, processes resulting from direct observation, such as emotion contagion or motor mimicry, can be excluded as explanations of our findings. After electrical stimulation of the participants, participants rated their own pain (self pain ratings: "How painful was this stimulus for you?"), using a 7 point rating scale ranging from "not at all" to "extremely painful." After stimulation of the other person, participants rated the other person's pain (other pain ratings: "How painful was this stimulus for the other person?") using the same 7 point rating scale as for the self pain ratings, as well as their own affect during stimulation of the other (unpleasantness ratings: "How unpleasant did it feel when the other person was stimulated?") using a 7 point scale, from "not at all” to "extremely unpleasant." In line with previous theoretical arguments about different aspects of empathy (see, e.g., Shamay-Tsoory, 2011; Lamm et al., 2015), we used two distinct behavioral measures. While the rating of how much pain the other person was feeling tapped into cognitiveevaluative aspects of the empathic response, the unpleasantness rating was used to cover aspects of affective sharing by measuring selfexperienced emotions. It is important to stress that the latter might also be influenced by personal distress (i.e., negative affect triggered by the aversive situation of someone else's pain). Such self-related vicarious responses are not confounds, but rather are an essential part of the empathic response (e.g., Batson et al., 1987; Decety and Lamm, 2011). They even seem to be a strong predictor of helping behavior, especially if they are appropriately regulated, and might have even been the evolutionary precursor of more mature consequences of empathy, such as sympathy and compassion (for review, see, e.g., Preston and de Waal, 2002; Singer and Klimecki, 2014).

In total, 40 trials of each condition (i.e., self pain, self no pain; other pain, other no pain) were run, presented in a pseudo-randomized sequence. Ratings were collected in approximately one-third of the trials, in a pseudo-randomized fashion.

\section{Procedures}

Before the testing day, participants filled in online versions of trait empathy questionnaires: Interpersonal Reactivity Index (Davis, 1983); Emotional Contagion Scale (Doherty, 1997). After arrival to the laboratory in pairs of two, participants were introduced to each other. One of them was a confederate, who was always female. At the outset of the experiment, all participants underwent a psychophysical pain calibration procedure (similar to the one used by Chan et al., 2012). The aim of this procedure was to determine reliable electrical stimulation intensities for painful and nonpainful stimuli. To this end, a series of stimuli was presented, and after each stimulation, participants had to rate their pain 


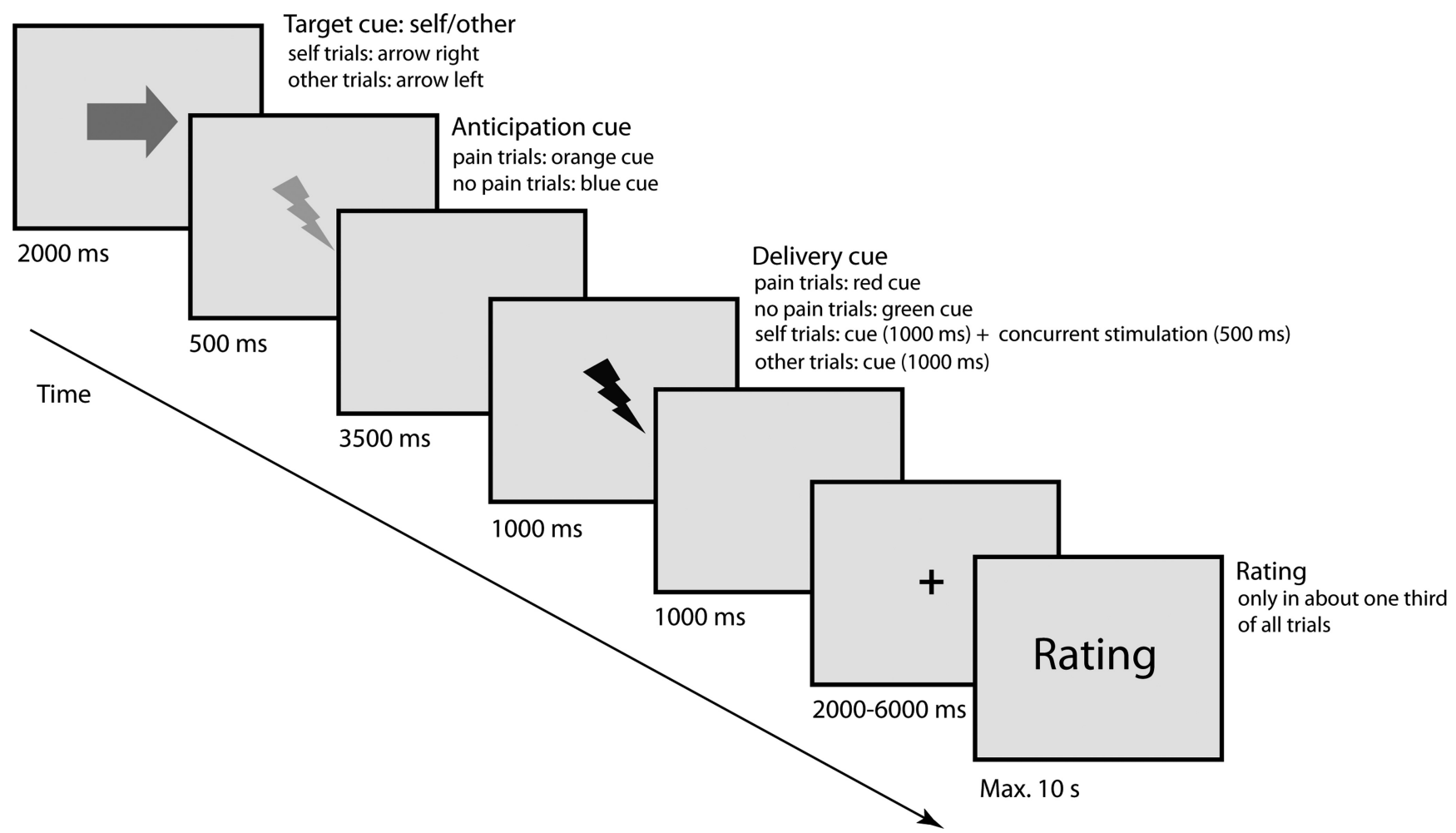

Figure 1. Structure and timeline of one trial of the experiment. An arrow cue indicating the target of the upcoming electric stimulation was followed by an anticipation cue indicating the intensity of the upcoming electric stimulus: orange flash represents painful; blue flash represents nonpainful. After a fixed interval of $3500 \mathrm{~ms}$, a delivery cue (duration $=1000 \mathrm{~ms}$ ) was presented concurrently with stimulus delivery (duration $=500 \mathrm{~ms}$ ): red flash represents painful; green flash represents nonpainful. Afterwards, affect ratings were collected in approximately one-third of all trials.

experience on a 7 point scale ranging from 1 ("perceptible”) but clearly nonpainful sensation to 7 ("unbearable pain"). As painful stimuli, we chose those stimuli that had been consistently rated with a value of 6 (corresponding to "extremely painful, but bearable"), whereas nonpainful stimuli were consistently rated with 1 ("perceptible stimulation, but not painful at all").

After calibration, participants of the placebo group were introduced to a medical doctor. She administered the placebo pill and informed participants that the "medication" was an approved, highly effective as well as expensive pain killer (as placebos perceived as more expensive have been shown to be more effective) (Waber et al., 2008). To increase effectiveness of the analgesia induction procedure, the MD also conveyed that the purpose of the study was not to test the effectiveness of the medication, as this had already been clearly established. Participants were then asked to rate the question: "Do you expect this medication to be effective in reducing your pain?" on a scale from 1 ("not at all") to 7 ("very effective"). After 15 min waiting time (allegedly for the medication to take effect), the placebo effect was amplified by a conditioning procedure commonly used and proven to be highly effective in placebo analgesia studies (Price et al., 1999). Specifically, participants were exposed to a series of four stimuli delivered with a current intensity of stimuli that had been rated as 3 or 4 during the calibration procedure (corresponding to medium levels of pain). However, participants were led to believe that they received stimuli they had previously rated as 6 (i.e., "extremely painful, but bearable"). After this conditioning procedure, participants were asked again to rate the question: "How effective is this medication in reducing your pain?" The confederate did not receive any medication, and this was expressly declared to participants. Participants and confederate were jointly seated in the EEG recording chamber, only separated by a black curtain to prevent direct observation of each other. The experiment proper took $\sim 40 \mathrm{~min}$ in total, and painful stimuli were delivered with the previously calibrated intensity of 6 . At the end of the experiment, postexperimental questionnaires were filled in, and participants were debriefed. The postexperimental questionnaires included ratings (rating scale ranging from 1 to 9 ) of how similar the participant felt to the other person, how much she was liked and how much the participant wished to affiliate with her, and how much strength, neediness, and agreeableness the participants attributed to her.

Because the aim of this study was to assess the effects of placebo analgesia on empathy for pain, it was crucial to determine for each individual that they were clearly responding to the placebo analgesia manipulation (i.e., that they reported substantially reduced pain when undergoing painful stimulation). We therefore used a combination of three measures to identify nonresponders. First and most importantly, doubts expressed about the analgesic effects of the medication or about pain medication in general (such as "usually I do not respond well to pain killers") were recorded. Second, belief scores about the effectiveness of the placebo before and after the placebo induction procedure were analyzed. Exceptionally low total belief scores (sum of both measures $<6$ ) and strong decreases between first and second measure $(>3)$ indicated a lack of responding. Third, we took the number of placebo induction trials into account: If participants responded with 6 (i.e., extremely painful) to the induction stimulus, we told them that we had to wait for another $5 \mathrm{~min}$ for the medication to take effect, and then tried again. This was performed until participants did not respond with 6 to the induction stimulus anymore. The number of inductions never exceeded 3 . All of the five excluded subjects of the placebo group met criterion 1 (doubts); two of them additionally met criterion 2 (exceptionally low belief scores; sums: 3 and 4, respectively); the remaining three additionally met criterion 3 (number of inductions $=3$ ).

\section{Electroencephalographic recordings}

Measurements were conducted in a sound-proof, light-attenuated and electrically shielded EEG chamber (Desone E:BOX, Desone Modulare Akustik). Participants were seated in a comfortable chair in $\sim 70 \mathrm{~cm}$ distance to the 21 inch cathode ray tube monitor (Sony GDM-F520) on which visual stimuli were presented (refresh rate $=75 \mathrm{~Hz}$ ). For presentation of the stimuli, MATLAB version 7.9.0 (The MathWorks) and the MATLAB toolbox Cogent (Version 1.32, The MathWorks; www.vislab. ucl.ac.uk/cogent.php) were used. EEG was recorded using a 64 channel 
full-band DC-EEG amplifier system (NEURO PRAX, version 2.4.2) within a frequency range from 0 to $250 \mathrm{~Hz}$ and digitally stored with a sampling rate of $500 \mathrm{~Hz}$. The ground reference was placed at the nasion. EEG signals were sampled from 59 equidistant $\mathrm{Ag} / \mathrm{AgCl}$ ring electrodes mounted on an elastic cap (Easycap). Additional electrodes were placed above and below the left eye and at the outer canthi of both eyes to record vertical and horizontal electro-oculograms. We used skin-scratching and electrode conductive gel to keep impedances $<3 \mathrm{k} \Omega$, which was individually verified using an impedance meter.

\section{EEG data analysis}

Data analysis was performed offline using EEGLAB 11 (Delorme and Makeig, 2004), implemented in MATLAB version 7.10.0 (The MathWorks). Data were low-pass filtered $(30 \mathrm{~Hz})$ and rereferenced to the averaged mastoid signal. Afterward data were epoched, with respect to the delivery cue, from $-4.5 \mathrm{~s}$ to $9 \mathrm{~s}$. This allowed visual inspection of a large time window for artifact correction. After exclusion of trials with major artifacts, independent component analysis was performed to separate and remove signals related to eye movements, blinks, heart, and muscle activity. On average, $11.92 \%$ of trials were removed (placebo group: $11.59 \%$; control group: $12.29 \%$, no significant difference between groups, $p=0.768)$. Next, each epoch was baseline-corrected with respect to average voltage in the interval of $200 \mathrm{~ms}$ before the onset of the anticipation cue. We chose this baseline interval as it was not influenced by the knowledge of the intensity of the upcoming stimulus. In trials in which recordings of an individual channel were contaminated by artifacts, the signal of that channel was interpolated using spherical spline interpolation implemented in EEGLAB. Then, event-related averages were computed per participant and condition, starting from onset of delivery cue to $1000 \mathrm{~ms}$ after.

Analyses predominantly focused on the pain-related P2 (GarciaLarrea et al., 2003). Previous placebo ERP studies (Wager et al., 2006; Watson et al., 2007; Aslaksen et al., 2011; Lyby et al., 2011) consistently analyzed the P2 component on electrode $\mathrm{Cz}$. We determined the individual $\mathrm{P} 2$ potentials based on these studies and visual inspection of the grand average ERP waveforms. It is still a matter of debate whether the painrelated $\mathrm{P} 2$ overlaps with the $\mathrm{P} 3 \mathrm{a}$, a prominent ERP component related to attention modulation (Lorenz and Garcia-Larrea, 2003). Although some authors have argued that the pain-related P2 can be disentangled from the P3a (Dowman, 2004), and hence does not reflect a general attentional process, others do not support this assumption and hypothesize at least some shared mechanisms between the two components (Legrain et al., 2003). We had carefully considered this issue when designing our study (see also the approach of Wager et al., 2006). In particular, we deliberately did not vary the painful stimuli with respect to timing, duration, intensity, or expectancy, as these are all factors known to trigger P3a. Hence, it seems unlikely that our P2 findings were strongly confounded by P3a-like responses.

Additional analyses focused on the P1, which is an occipital ERP component indexing an early stage of low-level visual processing that has also been linked to top-down attentional processes (Taylor, 2002), and the visual N1 component (Vogel and Luck, 2000), which is associated with attention and discrimination processes.

\section{Statistical analyses}

Our general analysis approach for both behavioral and ERP data consisted of the following steps. First, we performed a mixed-model ANOVA, which aimed at assessing whether the experimental factors (for details, see below) produced significant variation in the data (with the focus being on main effects of factor group, and an interaction of group $X$ intensity, which would indicate that painful and nonpainful stimuli differed between placebo and control group). In case of significant effects, planned comparisons were used to test our main hypothesis, which was that the placebo manipulation resulted not only in a reduction of the first-hand experience of pain, but also of empathy for pain. These planned comparisons consisted of $t$ tests for independent samples, which first tested (as a manipulation check) whether painful stimuli delivered to the self differed between the placebo and the control group (i.e., self pain: placebo vs control), and then whether this was also the case for painful stimuli delivered to the other person (i.e., other pain: placebo vs control). Because both these tests assessed directed a priori hypotheses (i.e., placebo $<$ control), one-tailed significance levels were used to determine their significance. Finally, a third independent-samples $t$ test (two-tailed, no directed hypothesis) examined whether the reduction of empathy for pain was similar to the reduction of its first-hand experience: self pain ( placebo - control) versus other pain ( placebo - control). Additional post hoc pairwise comparisons were used in case of visible differences between individual conditions not covered by the planned comparisons. All statistical analyses met the requirements of parametrical statistical tests (i.e., normality distribution and homogeneity of variances) and were performed using SPSS version 18.0 (SPSS). SEM was used as a variance estimate in Figures 2 and 4.

Rating data. For the rating data, our analysis approach implied two separate ANOVAs. In the first, self and other pain ratings were analyzed using a mixed-model ANOVA with the between-subjects factor group (control vs placebo), and the within-subjects factors intensity (pain vs no pain) and target (self vs other). This ANOVA was then followed up by three independent-samples $t$ tests, and, if indicated by visual inspection of results, post hoc comparisons, as outlined above. The second ANOVA (factors group and intensity) analyzed the unpleasantness rating delivered in response to stimulation of the other person.

Possible habituation effects of pain ratings were assessed with a mixedmodel ANOVA with within-subjects factors time (first half of trials in the experiment vs last half of trials) and target (self vs other) and the between-subjects factor group (control vs placebo), performed on ratings of painful trials only. Habituation effects of unpleasantness ratings were assessed with a mixed-model ANOVA with within-subjects factor time (first half of trials in the experiment vs last half of trials) and the between-subjects factor group (control vs placebo), performed on ratings of painful trials only.

Correlations were assessed using the Pearson coefficient. Differences between groups in questionnaire data and in electrical stimulation intensities were assessed with independent-samples $t$ tests (two-tailed)

ERP data. $\mathrm{P} 2$ peaks were defined as the first major positive deflection within the interval of 200-400 ms following delivery cue onset. P2 amplitudes for each participant and condition were assessed as peak-to-peak difference from the preceding negative wave occurring between 100 and $250 \mathrm{~ms}$ after delivery cue (Bromm and Lorenz, 1998). Differences in P2 amplitude and peak latency were assessed at electrode $\mathrm{Cz}$ using a mixedmodel ANOVA with the between-subjects factor group (control vs placebo) and within-subjects factors intensity (pain vs no pain) and target (self vs other). In analogy to the behavioral data, we performed planned comparisons consisting of independent-samples $t$ tests. These tests specifically tested the a priori hypotheses that P2 for both the first-hand experience of pain and empathy for pain is modulated by the placebo analgesia procedure. This was assessed by two independent-samples $t$ tests comparing the P2 amplitudes of the two groups (P2 self pain: placebo vs control; P2 other pain: placebo vs control; both hypotheses: one-tailed testing of placebo $<$ control), and one $t$ test comparing the magnitude of these differences: P2 self pain (placebo - control) versus P2 other pain (placebo - control), nondirected, two-tailed.

Possible P2 habituation effects were assessed with a mixed-model ANOVA with within-subjects factors time (first half of trials in the experiment vs last half of trials) and target (self vs other) and the betweensubjects factor group (control vs placebo), performed on P2 amplitudes of painful trials only. Furthermore, to visualize the comparability of the scalp distribution of P2 in the self- and other-related conditions, we calculated topographic maps of the P2 component (topographic distribution of average potential at peak of P2) in these conditions separately for the placebo and control group, using the topoplot functions implemented in EEGLAB.

To assess the specificity of the $\mathrm{P} 2$ results, we further analyzed the visual P1 and N1 ERP components in response to the delivery and the anticipation cue. Both components are elicited by visual stimuli and peak over the occipital visual cortex. The amplitudes of $\mathrm{P} 1$ and N1 were, respectively, determined as the mean positive and negative (baseline-to-peak) ERP voltage within the time window of $80-120 \mathrm{~ms}$ (P1) and 140-180 ms (N1), after cue onset, on occipital electrodes L24 and R27 (approximately 
corresponding to electrode locations $\mathrm{PO} 7$ and PO8 in the international 10-10 system). Assuming that placebo analgesia would specifically affect only pain-related processes, and not domain-general perceptual processes, we predicted that these components should not show any modulation by placebo analgesia. This was tested by four separate (for the two ERPs and cue types) mixed-model ANOVAs with the between-subjects factor group (control vs placebo) and within-subjects factors intensity (pain vs no pain) and target (self vs other). Because of the absence of significant interaction terms (see Results), and no visible group differences, no follow-up pairwise comparisons were computed for any of these ANOVAs.

\section{Results}

\section{Subjective ratings}

The three-factorial mixed-model ANOVA of self and other pain ratings, by which participants indicated how painful a certain stimulus felt to themselves or may have felt to the other participant, revealed a main effect of intensity $\left(F_{(1,36)}=822.407\right.$, $p<0.001$, partial $\eta^{2}=0.958$; indicating higher ratings for painful than for nonpainful stimuli); a main effect of target $\left(F_{(1,36)}=11.675, p=0.002\right.$, partial $\eta^{2}=$

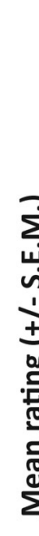

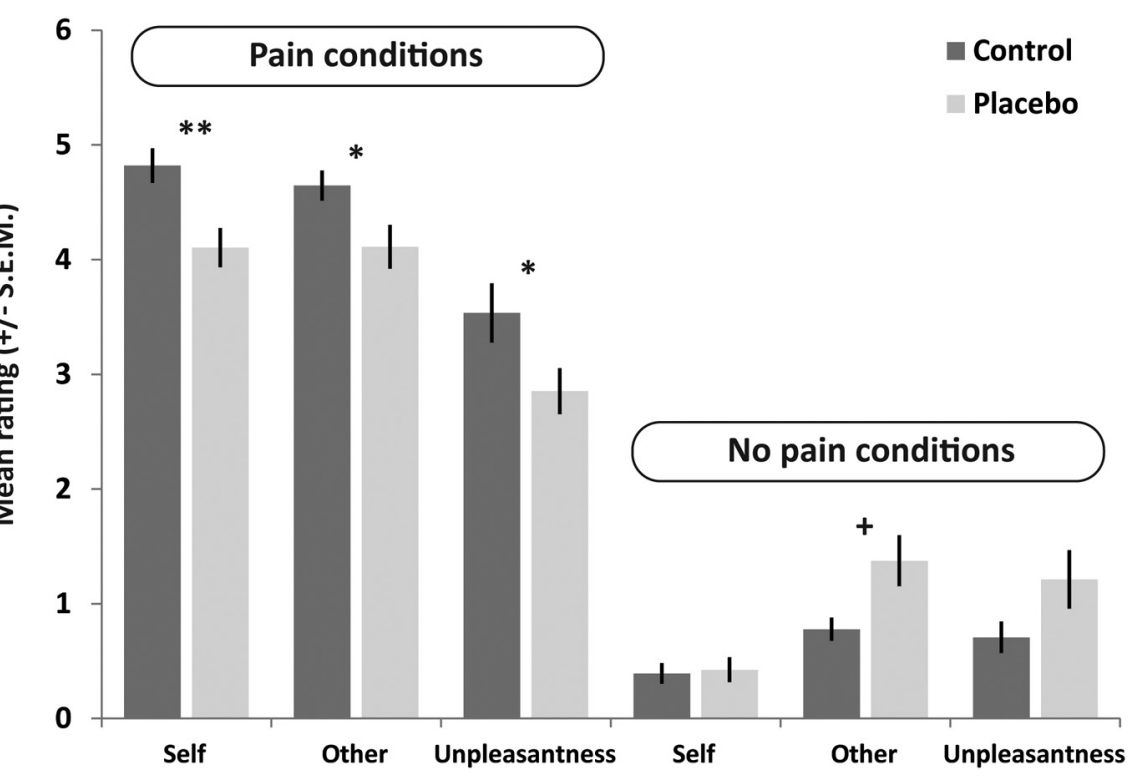

Figure 2. Self-report ratings (mean \pm SEM) in the placebo $(n=20)$ and control group $(n=18)$, for pain and no pain conditions and the different types of ratings (self pain, other pain, unpleasantness in response to other's pain). ${ }^{*} p<0.05$; ${ }^{* *} p<$ 0.01 (significant planned comparisons, independent-samples $t$ tests, of the main hypothesis that placebo analgesia reduced both self-experienced pain and empathy for pain). ${ }^{+} p<0.05$ (significant post hoc comparison for pain ratings to nonpainful stimulation).

0.245 ; determined by higher ratings in the self compared with the other conditions); and an intensity $\times$ group interaction $\left(F_{(1,36)}=\right.$ $13.001, p=0.001$, partial $\left.\eta^{2}=0.265\right)$. In addition, there was an intensity $\times$ target interaction $\left(F_{(1,36)}=20.316, p<0.001\right.$, partial $\left.\eta^{2}=0.361\right)$ and a trend for a target $\times$ group interaction $(p=$ $0.059)$, whereas the target $\times$ intensity $\times$ group interaction $(p=$ $0.423)$, and the main effect of group ( $p=0.354)$ were not significant. For illustration of significant effects, see Figure 2.

Importantly, the significant intensity $\times$ group interaction indicated that both groups differed in the pain but not in the no pain conditions. We thus performed planned independentsamples $t$ tests comparing the placebo and control group. This revealed a significant group difference for both the self-related pain $\left(t_{(1,36)}=3.124, p=0.002\right.$, Cohen's $\left.d=1.04\right)$ and the otherrelated pain conditions $\left(t_{(1,36)}=2.276, p=0.015\right.$, Cohen's $d=$ $0.76)$. Importantly, the magnitude of these differences did not differ significantly $\left(t_{(1,36)}=0.852, p=0.400\right)$. Visual inspection suggested a group difference for the other nonpainful condition, which was confirmed by a post hoc comparison $\left(t_{(1,36)}=2.075\right.$, $p=0.045$, Cohen's $d=0.69)$. No difference was visible for the self nonpainful condition.

The ANOVA of unpleasantness ratings, by which participants indicated the degree of negative affect triggered by witnessing the other participant's stimulation, revealed a main effect of intensity $\left(F_{(1,36)}=158.870, p<0.001\right.$, partial $\eta^{2}=0.815$; higher unpleasantness ratings for pain compared with no pain stimuli), a significant intensity $\times$ group interaction $\left(F_{(1,36)}=11.200, p=0.002\right.$, partial $\left.\eta^{2}=0.237\right)$, but no main effect of group ( $\left.p=0.728\right)$. Following up the significant two-way interaction, the independent-samples $t$ test revealed that unpleasantness ratings of the two groups differed for the pain condition $\left(t_{(1,36)}=1.850\right.$, $p=0.037$, Cohen's $d=0.61)$, indicating that the placebo group experienced less unpleasant affect when witnessing the other person's pain than the control group (Fig. 2). Visual inspection suggested a group difference for the no pain unpleasantness condition, which was not confirmed by a post hoc comparison $\left(t_{(1,36)}=1.344, p=0.187\right)$.

\section{Questionnaires}

Neither the two-sample $t$ tests on trait empathy measures differences (all $p$ values $>0.213$ ) nor the ones on the postexperimental ratings (all $p$ values $>0.233$ ) showed any significant group differences.

\section{Habituation analyses}

The three-factorial mixed-model ANOVA for pain ratings revealed neither a main effect of time $(p=0.539)$ nor any interactions with time (all $p$ values $>0.210$ ), indicating that pain ratings did not show habituation. The only significant finding was a main effect of group $\left(F_{(1,36)}=8.540, p=0.006\right.$, partial $\left.\eta^{2}=0.192\right)$, corresponding to the result reported above that the placebo group showed lower pain ratings than the control group.

The two-factorial mixed-model ANOVA for unpleasantness ratings in response to painful stimuli revealed neither a main effect of time $(p=0.752)$ nor a group $\times$ time interaction $(p=$ 0.725 ), indicating that unpleasantness ratings did not show habituation. As for the pain ratings, we found a main effect of group $\left(F_{(1,36)}=4.505, p=0.041\right.$, partial $\left.\eta^{2}=0.111\right)$.

\section{Pain thresholds}

Comparison of the individually calibrated stimulation intensities (determined before placebo induction) delivered by the pain stimulator did not reveal significant group differences (pain: $t_{(36)}$ $=0.677, p=0.503$; control group $0.824 \mathrm{~mA}$, placebo group 1.017 $\mathrm{mA}$; no pain: $t_{(36)}=0.171, p=0.865$, control group $0.131 \mathrm{~mA}$, placebo group $0.136 \mathrm{~mA}$ ). When delivered via concentric electrodes (as used here), such intensities have been shown to specifically activate nociceptive A $\delta$ fibers (Katsarava et al., 2006).

\section{Effectiveness ratings}

Ratings of expected analgesia after placebo delivery and after the conditioning procedure ranged between 1 ("not at all") and 6 ("very effective"). Mean ratings increased from 4.10 (SD: 0.98) 

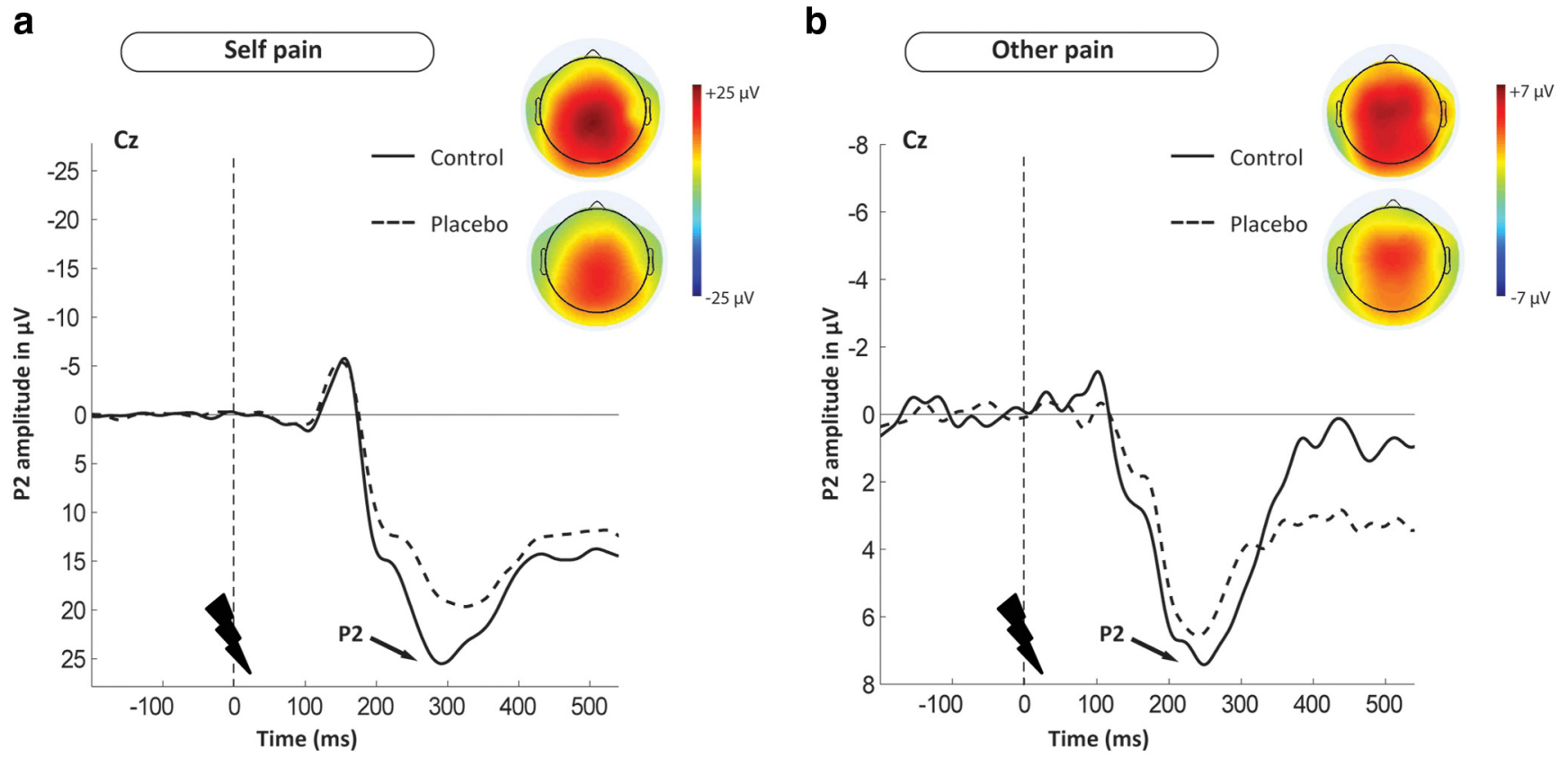

Figure 3. Illustration of the time course and scalp distribution of the pain-related P2 ERP component, using grand mean waveform plots (of electrode ( $Z$ ), and topographic maps, for the placebo group (dashed line, bottom topographic maps, $n=20$ ) and the control group (solid line, top topographic maps, $n=18$ ). $\boldsymbol{a}$, P2 related to the first-hand experience of pain. $\boldsymbol{b}, \mathrm{P} 2$ related to empathy for pain. Both waveform and scalp topographies indicate group differences in P2, in both conditions. Topographic maps show similar scalp distributions of P2 across conditions, and that placebo analgesia reduced the amplitude of this distribution in both conditions alike. Negative is plotted upward, by convention.

Table 1. P2 mean amplitudes $(\mu \mathrm{V})^{a}$

\begin{tabular}{lll}
\hline Condition & Control group $(n=18)$ & Placebo group $(n=20)$ \\
\hline Self pain & $38.28(3.60)$ & $28.34(2.05)$ \\
Self no pain & $17.50(1.69)$ & $15.64(1.41)$ \\
Other pain & $12.87(1.17)$ & $9.75(0.66)$ \\
Other no pain & $8.49(1.02)$ & $8.39(0.88)$ \\
\hline
\end{tabular}

${ }^{a}$ Data are mean (SEM).

after delivery of the pill ("Do you expect this medication to be effective in reducing your pain?") to 4.47 (SD: 1.47) after the conditioning procedure ("How effective is this medication?"). However, this increase was not significant $\left(t_{(19)}=0.884, p=0.388\right)$.

\section{ERP amplitudes and latencies}

Modulation of $P 2$ by placebo analgesia

Delivery of painful stimuli in both conditions resulted in clearly distinguishable P2 waveforms, showing the highest peak over centromedial scalp electrodes with an amplitude maximum at $\mathrm{Cz}$. As revealed by topographic mapping, the P2 scalp distribution was similar for both self and other-related pain (Fig. $3 a, b$ ), with the slightly more posterior peak for self-related pain being probably related to actual somatosensory stimulation in this condition. Moreover, the general pattern of the topographic maps was very similar for the two groups, while also indicating lower amplitude in the placebo group, for both conditions alike. For illustration of these effects, see the ERP waveforms and topographic plots in Figure $3 a, b$, as well as the mean amplitudes of P2 for all conditions listed in Table 1.

The three-factorial mixed-model ANOVA on P2 amplitudes revealed a main effect of intensity $\left(F_{(1,36)}=80.604, p<0.001\right.$, partial $\left.\eta^{2}=0.691\right)$, reflecting generally higher amplitudes for painful compared with nonpainful stimuli, and a main effect of target $\left(F_{(1,36)}=156.483, p<0.001\right.$, partial $\left.\eta^{2}=0.813\right)$, driven by higher amplitudes for self-related compared with other-related conditions. Importantly, the ANOVA also revealed a main effect of group $\left(F_{(1,36)}=5.720, p=0.022\right.$, partial $\left.\eta^{2}=0.137\right)$, driven by higher amplitudes across conditions in the control group, which was additionally qualified by an intensity $\times$ group interaction $\left(F_{(1,36)}=6.452, p=0.016\right.$, partial $\left.\eta^{2}=0.152\right)$. Further effects included an intensity $\times$ target interaction $\left(F_{(1,36)}=\right.$ 46.354, $p<0.001$, partial $\left.\eta^{2}=0.563\right)$, whereas the target $\times$ group interaction $(p=0.083)$ and the target $\times$ intensity $\times$ group three-way interaction $(p=0.222)$ were not significant.

The significant intensity $\times$ group interaction revealed that the groups differed in P2 amplitudes evoked by painful stimulation, but that no such difference occurred in response to nonpainful stimuli (Fig. 4; Table 1). We therefore performed planned independent-samples $t$ tests comparing the placebo and control groups. This revealed a significant group difference in $\mathrm{P} 2$ for both the self-related pain condition $\left(t_{(1,36)}=2.460, p=0.01\right.$, Cohen's $d=0.82)$ and the other-related pain condition $\left(t_{(1,36)}=2.383\right.$, $p=0.012$, Cohen's $d=0.79)$, and that the magnitude of these differences did not differ significantly $\left(t_{(1,36)}=1.707, p=0.096\right)$. Moreover, visual inspection (Fig. 4) indicated no significant group differences in either of the nonpainful conditions.

\section{P2 peak latency}

ANOVAs of P2 peak latency did not reveal any group-related latency differences (all $p$ values $>0.407$ ).

\section{Habituation of $P 2$}

The three-factorial mixed-model ANOVA testing for changes in P2 amplitudes between the first and the second half of the experiment revealed a significant main effect of time $\left(F_{(1,36)}=9.363\right.$, $p=0.004$, partial $\left.\eta^{2}=0.206\right)$, driven by higher amplitudes in the first compared with the second half of the experiment, and a main effect of target $\left(F_{(1,36)}=118.817, p<0.001\right.$, partial $\left.\eta^{2}=0.767\right)$, driven by higher amplitudes in response to self-related compared with other-related stimuli. In addition, a significant main effect of group $\left(F_{(1,36)}=8.205, p=0.007\right.$, partial $\left.\eta^{2}=0.186\right)$ revealed generally higher amplitudes in the control group. A significant 
time $\times$ target interaction $\left(F_{(1,36)}=4.804\right.$, $p=0.035$, partial $\eta^{2}=0.118$ ) was found, which was driven by lower P2 habituation in response to other-related compared with self-related stimulation. Importantly, the nonsignificant time $\times$ group interaction $(p=0.560)$ showed the absence of group-related habituation effects. All other interactions remained nonsignificant (all $p$ values $>0.087$ ).

Correlation of behavior and ERPs

None of the correlations between subjective ratings and ERPs was significant (all $p$ values $>0.128$ ).

\section{Specificity of results: $P 1$ and N1}

Grand average waveforms revealed negative and positive peaks of P1 and N1 at 100 and $160 \mathrm{~ms}$, respectively. Topographic plots of both components showed bilateral maxima over the occipital cortex, at electrodes L24 and R27 (approximately corresponding to electrode locations PO7 and PO8 in the international 10-10 system).

Importantly, neither P1 nor N1 differed between groups, as shown by the absence of significant main effects and interactions with the group factor in all ANOVAs (of P1 and N1 to anticipation and delivery cues). More specifically, the following findings were revealed by the separately performed ANOVAs.

Anticipation cue $P 1$. The only significant effect was a main effect of target $\left(F_{(1,36)}=5.450, p=0.025\right.$, partial $\left.\eta^{2}=0.131\right)$, driven by higher amplitudes in response to other-directed compared with self-directed stimulation. All other effects were nonsignificant (all $p$ values $>0.106 ; p$ values with factor group $>0.618$ ).

Anticipation cue N1. The ANOVA revealed a main effect of target $\left(F_{(1,36)}=25.160, p<0.001\right.$, partial $\left.\eta^{2}=0.411\right)$, driven by higher amplitudes in response to self-directed compared with other-directed stimulation. There was also a trend for a main effect of intensity $(p=0.052)$, as well as for the target $\times$ intensity interaction $(p=0.057)$. All other effects were nonsignificant (all $p$ values $>0.347 ; p$ values with factor group $>0.347$ ).

Delivery cue $P 1$. The ANOVA revealed a main effect of target $\left(F_{(1,36)}=11.087, p=0.002\right.$, partial $\left.\eta^{2}=0.235\right)$, which was related to higher amplitudes in response to other-directed compared with self-directed stimuli, and a target $X$ intensity interaction $\left(F_{(1,36)}=5.883, p=0.020\right.$, partial $\left.\eta^{2}=0.140\right)$, which was related to higher amplitudes in response to other pain stimuli compared with all other kinds of stimuli. All other effects were nonsignificant (all $p$ values $>0.206$; $p$ values with factor group $>0.464)$.

Delivery cue N1. The ANOVA revealed a main effect of target $\left(F_{(1,36)}=21.799, p<0.001\right.$, partial $\left.\eta^{2}=0.377\right)$, which was related to higher amplitudes in response to self-directed compared with other-directed stimuli; a main effect of intensity $\left(F_{(1,36)}=63.662, p<0.001\right.$, partial $\left.\eta^{2}=0.639\right)$, reflecting higher amplitudes in response to painful stimuli than to nonpainful stimuli; and a target $X$ intensity interaction $\left(F_{(1,36)}=14.478, p=\right.$ 0.001 , partial $\left.\eta^{2}=0.287\right)$, which was related to higher amplitudes in response to self pain stimuli compared with all other kinds of stimuli. All other effects were nonsignificant (all $p$ values $>0.117 ; p$ values with factor group $>0.117$ )

\section{Discussion}

The aim of our study was to experimentally manipulate the first-hand experience of pain and to test whether this also affects empathy for pain. Our results reveal, for the first time, the phenomenon of placebo empathy analgesia. Both behavioral and neural measures indicate that participants of the placebo group not only showed reduced responses when experiencing pain themselves, but also when pain was inflicted in another person. Importantly, participants not only evaluated the pain of the other person to be less severe (as shown by "other pain" ratings), but also showed a reduction in selfexperienced negative emotions in this condition (as shown by "unpleasantness" ratings). The latter are the most specific measure of empathy in the sense of affective sharing (see, e.g., Singer and Lamm, 2009), as they captured how someone feels in response to another person's feelings. Crucially, the selfreport findings were confirmed by the neural measurements. Topographic mapping of the P2 showed a striking similarity for both self and other-related pain conditions, suggesting that similar neural processes were recruited. Also, group differences regarding P2 amplitude were indicated by the topographic plots. Statistical analyses confirmed the mapping results, by indicating modulation of $\mathrm{P} 2$ by placebo analgesia in both self and other-related painful stimulation. Notably, both self-report and P2 indicated group differences of large effect size, as reflected by effect size measures in the ANOVAs and, crucially, all planned comparisons (all Cohen's $d$ very close to or >0.8; Cohen, 1988). Moreover, self-report and P2 in both conditions were modulated to a similar extent by placebo analgesia, providing further evidence of the engagement of similar functions in empathic and direct pain experiences.

Reductions of P2 amplitude by placebo analgesia have been attributed to modulation of the affective-motivational component of pain in the MCC (Wager et al., 2006), which suggests that placebo analgesia predominantly modulates this component of pain (e.g., Derbyshire, 2000; Legrain et al., 2011). A further indication of this interpretation is the generally higher P2 amplitude 
for self-related painful stimulation (Figs. 3, 4), which can be explained by higher affective-motivational salience and behavioral relevance of pain experienced by oneself.

The underlying neurochemical mechanism of $\mathrm{P} 2$ and its modulation is presumably the release of endogenous opioids, which are known to exert their analgesic effects by dampening the aversiveness of pain (Fuchs et al., 2014) and show particularly high receptor densities in MCC (Baumgärtner et al., 2006). We therefore propose that placebo empathy analgesia is underpinned by a dampening of the vicarious affective responses and that this is mediated by the opioid system. This dampened response is directly reflected in the unpleasantness ratings, which document that participants' own negative affect in response to the other's pain was lower in the placebo group. To substantiate this hypothesis on a mechanistic level, neuropharmacological studies are needed in which opioid agonists or antagonists are used to causally manipulate opioidergic function.

The between-subjects design of this study prevented us from testing whether participants with stronger placebo analgesia also show stronger reductions in empathy, which might be regarded as a potential limitation. However, we had deliberately decided against a within-subjects design to avoid repetition confounds, such as reductions in first-hand pain and empathy for pain with repeated stimulus exposure (which were confirmed by the habituation analyses for P2 during first-hand, but not empathy for pain). Between-subjects designs are less sensitive than within-subjects designs. Hence, the effects we report might actually be an underestimation of what might have been obtained in a within-subjects design.

The specificity of our findings is bolstered by a number of corollary analyses, showing, first, that $\mathrm{P} 1$ and N1 (low-level visual processing/attention) ERPs are not modulated by placebo analgesia. Given the lack of group differences during both anticipation and delivery phase in $\mathrm{P} 1$ and $\mathrm{N} 1$, it is unlikely that placebo analgesia changed general aspects of sensory perception or attention. Second, placebo analgesia also did not universally influence responses to any type of stimulation, as differences in P2 amplitudes were only observed for painful, but not for nonpainful control stimuli. This argument also applies to the subjective ratings of nonpainful stimuli, which were not affected by the placebo manipulation, with one exception: the placebo group rated higher relative levels of "pain" in the other no pain condition. This group difference, however, cannot be explained as a nonspecific reduction of responses to all kinds of stimuli, as this should have resulted in lower, and not in higher, ratings. Based on previous similar fMRI findings showing stronger ACC responses to nonpainful stimulation in the placebo analgesia compared with the control condition (Petrovic et al., 2002), we speculate that the placebo group subjectively experienced the nonpainful stimuli as more similar to the painful stimuli and therefore rated them accordingly. Finally, placebo analgesia also had no general effects on how participants perceived the other person, as the postexperimental questionnaire revealed no group differences related to liking, wish for affiliation, and perceived similarity with the confederate, nor with respect to attributions of strength, weakness, or neediness.

Together, the present results suggest that empathy indeed seems to rely upon neural processes that are (partially) functionally equivalent to those engaged by first-hand emotion experiences. Functional equivalence, as defined here, refers to the hypothesis that two conditions recruit neural processes and computations subserving essentially the same kind of psychological functions. It is important to stress, though, that only a subset of the involved neural functions shows such equivalence. In the present case, this seems to be the affective-motivational component of pain, whereas many other processes are only or more strongly recruited by the first-hand experience of pain and, hence, do not seem to play such an important role in empathy (e.g., nociceptive signals coded in posterior insular cortex) (for critical discussion, see Jackson et al., 2006; Decety, 2010).

Our findings strongly support social cognition models proposing that social perception is directly grounded in self-related representations and experiences, and relies on self-projection and simulation of others' emotions (Goldman, 2006; Bastiaansen et al., 2009; Mitchell, 2009; Singer and Lamm, 2009; Gallese and Sinigaglia, 2011). Previous neuroimaging studies had consistently shown that empathy recruits brain areas overlapping with those activated by the corresponding first-hand emotion experiences (for meta analysis, see, e.g., Lamm et al., 2011). The conclusions that could be drawn from such studies, however, were limited. Methodological constraints, for instance, preclude inferring that the spatially overlapping activations are indeed related to equivalent neural functions. Moreover, similar activations might also stem from processes that are not specifically related to the witnessed emotion, such as general emotional arousal or its regulation, triggered by exposure to an aversive stimulus (in this case, pain applied to oneself or to another person). Because of this lack of specificity, it so far remained unclear whether similar neural activations in empathy and first-hand emotion experiences indeed indicated empathic simulation. The present study takes us one step further toward this interpretation by demonstrating that placebo analgesia also resulted in a matching modulation of the behavioral and neural concomitants of empathy.

Whether empathy relies upon the engagement of equivalent brain functions is relevant on a number of levels. Conceptually, functional equivalence implies that the activation of emotional responses in the empathizer may serve a mechanistic role in simulating and hence in sharing another person's emotions. In addition, the engagement of equivalent functions in first-hand and empathic emotions might explain why both can be modulated by the same factors (e.g., cognitive appraisal and emotion regulation) (Hein and Singer, 2008). Functional equivalence also explains why empathy can be selectively affected by disorders associated with altered first-hand emotion experiences. For instance, empathy deficits in psychopathy and conduct disorders might be explained by alterations in the first-hand experience of fear (Marsh et al., 2013). Also, the selective empathy deficit of patients with congenital insensitivity to pain is limited to situations requiring direct somatic resonance, but not in cases such as inferring pain from facial expressions (Danziger et al., 2006). The latter finding is an important reminder that embodied simulation is certainly not the only mechanism of empathy, but that cognitive strategies, such as perspective taking and theory of mind, may help us to understand others in cases in which simulation is not feasible (Decety and Jackson, 2004; Singer, 2006; ShamayTsoory, 2011).

In conclusion, our study strongly supports theories proposing that self-projection grounded in one's own emotion representations is used as a proxy to share the emotions of others. On the down-side, this also implies that self-projection might result in egocentrically biased empathic judgments, if not appropriately supervised (O'Brien and Ellsworth, 2012; Silani et al., 2013; Steinbeis et al., 2015). The fact that placebo analgesia also modulates how we evaluate and resonate with the pain of others is another case of such an egocentric empathic bias. Of note, this may also have wider and important practical implications, as it suggests 
that painkillers will not only help us to deal with our own pain but may also reduce our concern for others' pain and suffering.

\section{References}

Aslaksen PM, Bystad M, Vambheim SM, Flaten MA (2011) Gender differences in placebo analgesia: event-related potentials and emotional modulation. Psychosom Med 73:193-199. CrossRef Medline

Bastiaansen JA, Thioux M, Keysers C (2009) Evidence for mirror systems in emotions. Philos Trans R Soc B Biol Sci 364:2391-2404. CrossRef Medline

Batson CD, Fultz J, Schoenrade PA (1987) Distress and empathy: two qualitatively distinct vicarious emotions with different motivational consequences. J Pers 55:19-39. CrossRef Medline

Baumgärtner U, Buchholz HG, Bellosevich A, Magerl W, Siessmeier T, Rolke R, Höhnemann S, Piel M, Rösch F, Wester HJ, Henriksen G, Stoeter P, Bartenstein P, Treede RD, Schreckenberger M (2006) High opiate receptor binding potential in the human lateral pain system. Neuroimage 30:692-699. CrossRef Medline

Becker DE, Yingling CD, Fein G (1993) Identification of pain, intensity and P300 components in the pain evoked potential. Electroencephalogr Clin Neurophysiol 88:290-301. CrossRef Medline

Benedetti F, Mayberg HS, Wager TD, Stohler CS, Zubieta JK (2005) Neurobiological mechanisms of the placebo effect. J Neurosci 25:10390-10402. CrossRef Medline

Bromm B, Lorenz J (1998) Neurophysiological evaluation of pain. Electroencephalogr Clin Neurophysiol 107:227-253. CrossRef Medline

Chan SC, Chan CC, Kwan AS, Ting KH, Chui TY (2012) Orienting attention modulates pain perception: an ERP study. PLoS One 7:e40215. CrossRef Medline

Cohen J (1988) Statistical power analysis for the behavioral sciences (ed 2). Hillsdale, NJ: Erlbaum.

Colloca L, Klinger R, Flor H, Bingel U (2013) Placebo analgesia: psychological and neurobiological mechanisms. Pain 154:511-514. CrossRef Medline

Danziger N, Prkachin KM, Willer JC (2006) Is pain the price of empathy? The perception of others' pain in patients with congenital insensitivity to pain. Brain 129:2494-2507. CrossRef Medline

Davis MH (1983) Measuring individual differences in empathy: evidence for a multidimensional approach. J Pers Soc Psychol 44:113-126. CrossRef

Decety J (2010) To what extent is the experience of empathy mediated by shared neural circuits? Emot Rev 2:204-207. CrossRef

Decety J, Jackson PL (2004) The functional architecture of human empathy. Behav Cogn Neurosci Rev 3:71-100. CrossRef Medline

Decety J, Lamm C (2011) Empathy vs personal distress. In: The social neuroscience of empathy (Decety J, Ickes W, eds), pp 199-214. Cambridge, MA: Massachusetts Institute of Technology.

Delorme A, Makeig S (2004) EEGLAB: an open source toolbox for analysis of single-trial EEG dynamics including independent component analysis. J Neurosci Methods 134:9-21. CrossRef Medline

Derbyshire SWG (2000) Exploring the pain "neuromatrix." Curr Rev Pain 4:467-477. CrossRef Medline

Doherty RW (1997) The emotional contagion scale: a measure of individual differences. J Nonverb Behav 21:131-154. CrossRef

Dowman R (2004) The pain-evoked P2 is not a P3a event-related potential. Brain Topogr 17:3-12. CrossRef Medline

Eisenberger NI (2015) Social pain and the brain: controversies, questions, and where to go from here. Annu Rev Psychol 66:601-629. CrossRef Medline

Fan Y, Duncan NW, de Greck M, Northoff G (2011) Is there a core neural network in empathy? An fMRI based quantitative meta-analysis. Neurosci Biobehav Rev 35:903-911. CrossRef Medline

Fuchs PN, Peng YB, Boyette-Davis JA, Uhelski ML (2014) The anterior cingulate cortex and pain processing. Front Integr Neurosci 8:35. CrossRef Medline

Gallese V, Sinigaglia C (2011) What is so special about embodied simulation? Trends Cogn Sci 15:512-519. CrossRef Medline

Garcia-Larrea L, Frot M, Valeriani M (2003) Brain generators of laserevoked potentials: from dipoles to functional significance. Neurophysiol Clin 33:279-292. CrossRef Medline

Goldman A (2006) Simulating minds: the philosophy, psychology and neuroscience of mindreading. New York: Oxford UP.

Grill-Spector K, Malach R (2001) fMR-adaptation: a tool for studying the functional properties of human cortical neurons. Acta Psychol (Amst) 107:293-321. CrossRef Medline

Hein G, Singer T (2008) I feel how you feel but not always: the empathic brain and its modulation. Curr Opin Neurobiol 18:153-158. CrossRef Medline

Hein G, Lamm C, Brodbeck C, Singer T (2011) Skin conductance response to the pain of others predicts later costly helping. PLoS One 6:e22759. CrossRef Medline

Hoffman GA, Harrington A, Fields HL (2005) Pain and the placebo: what we have learned. Perspect Biol Med 48:248-265. CrossRef Medline

Jackson PL, Rainville P, Decety J (2006) To what extent do we share the pain of others? Insight from the neural bases of pain empathy. Pain 125:5-9. CrossRef Medline

Katsarava Z, Ayzenberg I, Sack F, Limmroth V, Diener HC, Kaube H (2006) A novel method of eliciting pain-related potentials by transcutaneous electrical stimulation. Headache 46:1511-1517. CrossRef Medline

Lamm C, Majdandžić J (2015) The role of shared neural activations, mirror neurons, and morality in empathy: a critical comment. Neurosci Res 90:15-24. CrossRef Medline

Lamm C, Decety J, Singer T (2011) Meta-analytic evidence for common and distinct neural networks associated with directly experienced pain and empathy for pain. Neuroimage 54:2492-2502. CrossRef Medline

Lamm C, Silani G, Singer T (2015) Distinct neural networks underlying empathy for pleasant and unpleasant touch. Cortex. Advance online publication. Accessed Feb. 10, 2015. doi: 10.1016/j.cortex.2015.01.021. CrossRef Medline

Lefaucheur JP, Ahdab R, Ayache SS, Lefaucheur-Ménard I, Rouie D, Tebbal D, Neves DO, Ciampi de Andrade D (2012) Pain-related evoked potentials: a comparative study between electrical stimulation using a concentric planar electrode and laser stimulation using a $\mathrm{CO}_{2}$ laser. Neurophysiol Clin 42:199-206. CrossRef Medline

Legrain V, Guérit JM, Bruyer R, Plaghki L (2003) Electrophysiological correlates of attentional orientation in humans to strong intensity deviant nociceptive stimuli, inside and outside the focus of spatial attention. Neurosci Lett 339:107-110. CrossRef Medline

Legrain V, Iannetti GD, Plaghki L, Mouraux A (2011) The pain matrix reloaded: a salience detection system for the body. Prog Neurobiol 93:111124. CrossRef Medline

Lorenz J, Garcia-Larrea L (2003) Contribution of attentional and cognitive factors to laser evoked brain potentials. Neurophysiol Clin 33:293-301. CrossRef Medline

Lyby PS, Aslaksen PM, Flaten MA (2011) Variability in placebo analgesia and the role of fear of pain: an ERP study. Pain 152:2405-2412. CrossRef Medline

Marsh AA, Finger EC, Fowler KA, Adalio CJ, Jurkowitz IT, Schechter JC, Pine DS, Decety J, Blair RJ (2013) Empathic responsiveness in amygdala and anterior cingulate cortex in youths with psychopathic traits. J Child Psychol Psychiatry 54:900-910. CrossRef Medline

Mitchell JP (2009) Inferences about mental states. Philos Trans R Soc Lond B Biol Sci 364:1309-1316. CrossRef Medline

O’Brien E, Ellsworth PC (2012) More than skin deep: visceral states are not projected onto dissimilar others. Psychol Sci 23:391-396. CrossRef Medline

Perchet C, Godinho F, Mazza S, Frot M, Legrain V, Magnin M, Garcia-Larrea L (2008) Evoked potentials to nociceptive stimuli delivered by $\mathrm{CO}_{2}$ or Nd:YAP lasers. Clin Neurophysiol 119:2615-2622. CrossRef Medline

Perchet C, Frot M, Charmarty A, Flores C, Mazza S, Magnin M, Garcia-Larrea L (2012) Do we activate specifically somatosensory thin fibres with the concentric planar electrode? A scalp and intracranial EEG study. Pain 153:1244-1252. CrossRef Medline

Petrovic P, Kalso E, Petersson KM, Ingvar M (2002) Placebo and opioid analgesia: imaging a shared neuronal network. Science 295:1737-1740. CrossRef Medline

Poldrack RA (2006) Can cognitive processes be inferred from neuroimaging data? Trends Cogn Sci 10:59-63. CrossRef Medline

Preston SD, de Waal FB (2002) Empathy: its ultimate and proximate bases. Behav Brain Sci 25:1-20; discussion 20-71. Medline

Price DD, Milling LS, Kirsch I, Duff A, Montgomery GH, Nicholls SS (1999) An analysis of factors that contribute to the magnitude of placebo analgesia in an experimental paradigm. Pain 83:147-156. CrossRef Medline

Scott DJ, Stohler CS, Egnatuk CM, Wang H, Koeppe RA, Zubieta JK (2008) 
Placebo and nocebo effects are defined by opposite opioid and dopaminergic responses. Arch Gen Psychiatry 65:220-231. CrossRef Medline

Shackman AJ, Salomons TV, Slagter HA, Fox AS, Winter JJ, Davidson RJ (2011) The integration of negative affect, pain and cognitive control in the cingulate cortex. Nat Rev Neurosci 12:154-167. CrossRef Medline

Shamay-Tsoory SG (2011) The neural bases for empathy. Neuroscientist 17:18-24. CrossRef Medline

Silani G, Lamm C, Ruff CC, Singer T (2013) Right supramarginal gyrus is crucial to overcome emotional egocentricity bias in social judgments. J Neurosci 33:15466-15476. CrossRef Medline

Singer T (2006) The neuronal basis and ontogeny of empathy and mind reading: review of literature and implications for future research. Neurosci Biobehav Rev 30:855-863. CrossRef Medline

Singer T, Klimecki OM (2014) Empathy and compassion. Curr Biol 24: R875-R878. CrossRef Medline

Singer T, Lamm C (2009) The social neuroscience of empathy. Ann N Y Acad Sci 1156:81-96. CrossRef Medline

Singer T, Seymour B, O’Doherty J, Kaube H, Dolan RJ, Frith CD (2004) Empathy for pain involves the affective but not sensory components of pain. Science 303:1157-1162. CrossRef Medline

Singer T, Seymour B, O’Doherty JP, Stephan KE, Dolan RJ, Frith CD (2006)
Empathic neural responses are modulated by the perceived fairness of others. Nature 439:466-469. CrossRef Medline

Singer T, Snozzi R, Bird G, Petrovic P, Silani G, Heinrichs M, Dolan RJ (2008) Effects of oxytocin and prosocial behavior on brain responses to direct and vicariously experienced pain. Emotion 8:781-791. CrossRef Medline

Steinbeis N, Bernhardt BC, Singer T (2015) Age-related differences in function and structure of rSMG and reduced functional connectivity with DLPFC explains heightened emotional egocentricity bias in childhood. Soc Cogn Affect Neurosci 10:302-310. CrossRef Medline

Taylor MJ (2002) Non-spatial attentional effects on P1. Clin Neurophysiol 113:1903-1908. CrossRef Medline

Vogel EK, Luck SJ (2000) The visual N1 component as an index of a discrimination process. Psychophysiology 37:190-203. CrossRef Medline

Waber RL, Shiv B, Carmon Z, Ariely D (2008) Commercial features of placebo and therapeutic efficacy. JAMA 299:1016-1017. CrossRef Medline

Wager TD, Matre D, Casey KL (2006) Placebo effects in laser-evoked pain potentials. Brain Behav Immun 20:219-230. CrossRef Medline

Watson A, El-Deredy W, Vogt BA, Jones AK (2007) Placebo analgesia is not due to compliance or habituation: EEG and behavioural evidence. Neuroreport 18:771-775. CrossRef Medline 